\title{
The Rhesus Monkey Hippocampus Critically Contributes to Scene Memory Retrieval, But Not New Learning
}

\author{
[DSean Froudist-Walsh, ${ }^{1}$ Philip G.F. Browning, ${ }^{1}$ Paula L. Croxson, ${ }^{1}$ Kathy L. Murphy, ${ }^{1}$ Jul Lea Shamy, ${ }^{1}$ Tess L. Veuthey, \\ (1)Charles R.E. Wilson, ${ }^{2}$ and Mark G. Baxter ${ }^{1}$ \\ ${ }^{1}$ Glickenhaus Laboratory of Neuropsychology, Department of Neuroscience and Friedman Brain Institute, Icahn School of Medicine at Mount Sinai, \\ New York, New York 10029 and 'Univ Lyon, Université Claude Bernard Lyon 1, Inserm, Stem Cell and Brain Research Institute U1208, 69500 Bron, France
}

Humans can recall a large number of memories years after the initial events. Patients with amnesia often have lesions to the hippocampus, but human lesions are imprecise, making it difficult to identify the anatomy underlying memory impairments. Rodent studies enable great precision in hippocampal manipulations, but not investigation of many interleaved memories. Thus it is not known how lesions restricted to the hippocampus affect the retrieval of multiple sequentially encoded memories. Furthermore, disagreement exists as to whether hippocampal inactivations lead to temporally graded or ungraded amnesia, which could be a consequence of differences between rodent and human studies. In the current study, rhesus monkeys of both sexes received either bilateral neurotoxic hippocampal lesions or remained unoperated controls and were tested on recognition and new learning of visual object-in-place scenes. Monkeys with hippocampal lesions were significantly impaired at remembering scenes that were encoded before the lesion. We did not observe any temporal gradient effect of the lesion on memory recognition, with recent and remote memories being equally affected by the lesion. Monkeys with hippocampal lesions showed no deficits in learning new scenes. Thus, the hippocampus, like other cortical regions, may be engaged in the acquisition and storage of new memories, but the role of the damaged hippocampus can be taken over by spared hippocampal tissue or extra-hippocampal regions following a lesion. These findings illustrate the utility of experimental paradigms for studying retrograde and anterograde amnesia that make use of the capacity of nonhuman primates to rapidly acquire many distinct visual memories.

Key words: anterograde amnesia; episodic; macaque; memory; retrograde amnesia; rhesus

Significance Statement

Recalling old memories, creating new memories, and the process by which memories transition from temporary to permanent storage all may rely on the hippocampus. Whether the hippocampus is necessary for encoding and retrieval of multiple related visual memories in primates is not known. Monkeys that learned many visual memory problems before precise lesions of the hippocampus were impaired at recalling those memories after hippocampal damage regardless of when the memories were formed, but could learn new memory problems at a normal rate. This suggests the hippocampus is normally vital for retrieval of complex visual memories regardless of their age, and also points to the importance of investigating mechanisms by which memories may be acquired in the presence of hippocampal damage.

\section{Introduction}

When memory works, we recall important details of experiences years later. Widely distributed patterns of brain activity are con- solidated, so that a record of activity that would otherwise be forgotten is kept. The brain mechanisms of such "systems consolidation" point toward a pivotal role for the hippocampus. For more than 60 years the hippocampus has been a focus of investigation for memory research, due to the devastating anterograde

scans; Bill Janssen for help with perfusions; Richard Saunders for advice on the hippocampal neurosurgical approach; and David Gaffan for advice on experimental design.

The authors declare no competing financial interests.

Correspondence should be addressed to Dr. Mark G. Baxter, Department of Neuroscience, Icahn School of Medicine at Mount Sinai, One Gustave L. Levy Place, Box 1639, New York, NY 10029. E-mail: mark.baxter@mssm.edu. DOI:10.1523/JNEUROSCI.0832-18.2018

Copyright $\odot 2018$ the authors $\quad 0270-6474 / 18 / 387800-09 \$ 15.00 / 0$ 
amnesia experienced by Henry Molaison following surgical resection of the hippocampus (Scoville and Milner, 1957). Reassessment of the original lesions demonstrated that the affected area was much greater than initially thought (Augustinack et al., 2014), complicating the interpretation of the role of the hippocampus, and other brain regions, in human episodic memory. At the same time, studies of selective neurotoxic hippocampal lesions in rodents and monkeys suggest a more limited role for the hippocampus in anterograde memory, particularly object recognition memory (Murray and Mishkin, 1998; Baxter and Murray, 2001; Winters et al., 2004; Forwood et al., 2005; cf. Doré et al., 1998; Zola et al., 2000; Broadbent et al., 2010).

Considerable evidence on systems consolidation has come from studies in rodents using behavioral paradigms in which the time of learning is precisely defined, including inhibitory avoidance, contextual fear conditioning, and social transmission of food preference. Many of these experiments have implicated the hippocampus in retrieval of recent memories, within $24 \mathrm{~h}$, and, conversely, the anterior cingulate cortex for more remote memories, $\sim 1$ month old (Frankland et al., 2004, 2006; Teixeira et al., 2006; Ding et al., 2008). Highly "schematized" memories that are variations of a familiar memory task may become hippocampalindependent within hours (Tse et al., 2011). Multiple studies in humans have shown temporally limited retrograde amnesia after damage apparently limited to the hippocampus (Reed and Squire, 1998; Kapur and Brooks, 1999; Bayley et al., 2005b). Nevertheless, some studies point toward a more enduring role for the hippocampus in memory retrieval. For example, humans that suffer transient global amnesia show focal lesions in hippocampal region CA1 and retrograde amnesia that spans decades (Bartsch and Deuschl, 2010; Bartsch et al., 2011). Conflicting evidence from human and rodent studies as to the temporal gradient of amnesia could reflect a dissociation between transient and sustained hippocampal inactivation (Goshen et al., 2011), although conflicting human studies may result from the lack of experimental control over the brain area affected. It is thus not clear whether complete permanent lesions restricted to the hippocampus will lead to temporally graded or ungraded retrograde amnesia.

The hippocampus may coordinate neocortical activity rather than serve simply as a temporary memory store, as hippocampal inactivation impairs memory retrieval and reactivation of cortical neurons that were active at encoding (Tanaka et al., 2014) and direct reactivation of cortical neurons that were active at context encoding produces context-specific behavior even if the hippocampus is inactivated (Cowansage et al., 2014). Hippocampal memory traces may also remain active while complementary memory traces become established in the cortex (Moscovitch et al., 2005; Tayler et al., 2013), suggesting that in some cases hippocampal activation during memory retrieval may be commonplace, but not necessary.

We sought to overcome some of the limitations of human and rodent memory studies by examining retrieval and new learning of visual object-in-place scenes in rhesus monkeys after selective, bilateral neurotoxic lesions limited to the hippocampus. Objectin-place scene memory in monkeys is thought to closely model some aspects of human episodic memory (Gaffan, 1994; Mitchell et al., 2008). Monkeys with hippocampal lesions were significantly impaired at remembering scenes that were encoded before the lesion, but showed no deficits in learning new scenes. We did not observe any temporal gradient effect of the lesion on memory recognition, with recent and remote memories being equally affected by the lesion.

\section{Materials and Methods}

Subjects. Subjects were 17 rhesus macaque monkeys of both sexes (Macaca mulatta; mean age 3.9 years, range 2.7-5.1 years, mean weight at time of surgery or equivalent for unoperated controls $4.7 \mathrm{~kg}$, range $3.3-$ $7.4 \mathrm{~kg}$ ). Four male monkeys received bilateral neurotoxic hippocampal lesions as described below. The other monkeys ( 3 female, 10 male) acted as unoperated controls. These experiments were performed under either the authority of personal and project licenses consistent with the United Kingdom Animals (Scientific Procedures) Act 1986, or a protocol approved by the Institutional Animal Care and Use Committee of the Icahn School of Medicine at Mount Sinai. The four monkeys with neurotoxic hippocampal lesions and four of the controls (all male) were tested at Mount Sinai; the remaining monkeys were tested at Oxford University. Data from some of the control monkeys has appeared in previous publications (Mitchell et al., 2008).

Hippocampal lesions. Monkeys received MRI-guided bilateral neurotoxic hippocampal lesions using methods described by (Hampton et al., 2004). Neurosurgical procedures were performed in a dedicated operating theater under aseptic conditions. Briefly, monkeys were sedated with a mixture of dexmedetomidine $(0.01 \mathrm{mg} / \mathrm{kg})$, buprenorphine $(0.01 \mathrm{mg} /$ $\mathrm{kg})$ and midazolam $(0.1 \mathrm{mg} / \mathrm{kg})$ given intramuscularly. Where necessary, top-ups were given of dexmedetomidine $(0.003 \mathrm{mg} / \mathrm{kg})$ and midazolam $(0.1 \mathrm{mg} / \mathrm{kg}$ ) without buprenorphine (to avoid excessive respiratory depression) and any further top-ups of dexmedetomidine $(0.003 \mathrm{mg} / \mathrm{kg})$ only as necessary. This protocol was selected to avoid the use of the NMDA antagonist ketamine, which would potentially counteract the effects of the NMDA used as an excitotoxin (Hampton et al., 2004).

Monkeys were intubated, an intravenous catheter placed and anesthesia was maintained with sevoflurane (1.5-4\%, to effect, in 100\% oxygen). Monkeys were given glycopyrrolate $(0.01 \mathrm{mg} / \mathrm{kg}$, i.m.), antibiotics (Cefazolin, $25 \mathrm{mg} / \mathrm{kg}$, i.m.), steroids (methylprednisolone, $20 \mathrm{mg} / \mathrm{kg}$, i.v.), nonsteroidal anti-inflammatories (meloxicam, $0.2 \mathrm{mg} / \mathrm{kg}$, i.v.), and an $\mathrm{H} 2$ receptor antagonist (ranitidine, $1 \mathrm{mg} / \mathrm{kg}$, i.v.) to prevent against gastric ulceration following the administration of both steroids and nonsteroidal anti-inflammatories. Atipamezole was used to antagonize the $\alpha 2$-adrenergic agonist if necessary, once anesthesia was stabilized. Monkeys received intravenous fluids throughout the procedure $(5 \mathrm{ml} / \mathrm{kg} / \mathrm{h}$, i.v. $)$.

The monkey was placed in a stereotaxic frame in exactly the same position as for the preoperative structural MRI scan (using a tooth marker; Saunders et al., 1990). The head was cleaned with antimicrobial cleaner and the skin and underlying galea were opened in layers. Small holes were drilled over the injection entry points: one dorsal and posterior to the long axis of the hippocampus and one dorsal to the uncus in each hemisphere (Hampton et al., 2004). Two micromanipulators (Kopf Instruments) were fitted with gas-tight syringes (Hamilton) with a 28 gauge needle, point style 4 , using measurements obtained from the preoperative T1-weighted scan at the most anterior extent of the hippocampus and injections of NMDA ( $0.3 \mathrm{~m}$ in sterile saline) were made from anterior to posterior, spaced $1.5 \mathrm{~mm}$ apart. Each injection was $1.5-2 \mu \mathrm{l}$ in volume, made at a rate of $0.5 \mu \mathrm{l} / \mathrm{min}$, with $1 \mathrm{~min}$ between targets. After the final injection the needle was raised $0.5 \mathrm{~mm}$ and $10 \mathrm{~min}$ elapsed before it was extracted. For the uncus injections two injections per hemisphere were made, $3 \mu \mathrm{l}$ in volume, made at a rate of $0.5 \mu \mathrm{l} / \mathrm{min}$, with 3 min between targets. Propanolol $(0.5 \mathrm{ml}$ of $1 \mathrm{mg} / \mathrm{ml}$ per dose $)$ was administered immediately before the NMDA injections and readministered as necessary (up to 4 times) to prevent tachycardia during the injections due to nonspecific effects of NMDA. One monkey received propofol during one surgery $(4.0 \mathrm{ml}$ total in boluses of $0.5-1.0 \mathrm{ml}$ of a 10 $\mathrm{mg} / \mathrm{ml}$ solution) to supplement anesthesia, due to tachypnoea, also likely to be a nonspecific effect of NMDA. Once the lesion was completed the skin and galea were sewn in layers.

When the lesion was complete, monkeys received $0.2 \mathrm{mg} / \mathrm{kg}$ metoclopramide (i.m.) to prevent postoperative vomiting. Monkeys also received $0.1 \mathrm{mg} / \mathrm{kg}$ midazolam (i.m.) to prevent seizures. They were extubated when a swallowing reflex was evident, returned to the home cage, and monitored continuously until normal posture was regained. Postoperatively monkeys were treated with antibiotics, steroids, and an- 

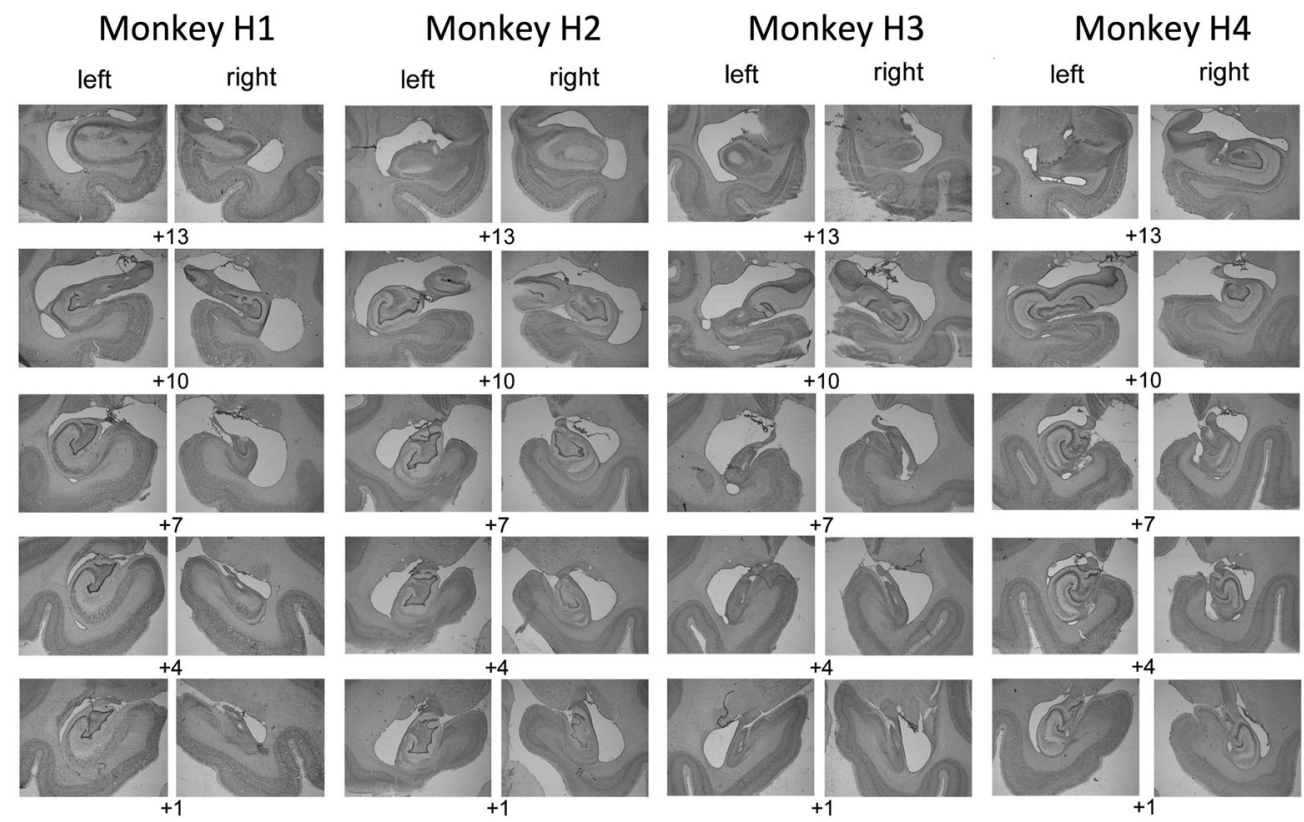

Figure 1. Hippocampal lesion histology. Lesions were specific to the hippocampus in both hemispheres. Cresyl violet stained sections showing the extent of hippocampal lesions in four operated monkeys. Numerals indicate $\mathrm{mm}$ anterior to the interaural plane.

algesia for 3-5 $\mathrm{d}$. Operated monkeys were returned to their social groups within $3 \mathrm{~d}$ of the surgery.

Following the first surgery we assessed the lesion extent in each monkey with a T2-weighted scan (Málková et al., 2001) and used the result to plan a second surgery, targeting the injection coordinates to regions with low hypersignal. All monkeys received two surgeries.

Histology. At the end of the study, monkeys were deeply anesthetized with ketamine $(10 \mathrm{mg} / \mathrm{kg}$ ), intubated, and given sodium barbiturate (sodium pentobarbital, $100 \mathrm{mg} / \mathrm{kg}$ ) intravenously. They were then transcardially perfused with $0.9 \%$ saline followed by $4 \%$ paraformaldehyde. Brains were postfixed in paraformaldehyde overnight and then cryoprotected in $30 \%$ sucrose solution in $0.9 \%$ saline and cut into $50 \mathrm{~m}$ sections coronally on a freezing microtome. One in five sections was stained with cresyl violet for cell bodies. The sections containing the hippocampus were photographed using a Nikon Eclipse $80 \mathrm{i}$ light microscope with a $4 \times$ objective (Fig. 1).

Hippocampal lesion volume assessment was performed in Fiji (https:// fiji.sc/), a version of the image analysis program ImageJ. The volume of the hippocampus was manually delineated on sections of the monkey atlas "Red" (using criteria from Málková et al., 2001) and the remaining hippocampal volume of the hippocampus was manually delineated on images of the cresyl violet sections. The sections were then nonlinearly warped to the atlas using the function bUnwarpJ and the lesion volume was calculated as the difference between the atlas hippocampal volume and the remaining volume of hippocampal tissue (Table 1). This may be an underestimate of the true extent of the lesion as some damaged cells are likely included in the remaining hippocampal volume, rather than the lesion volume. The overlap between the remaining hippocampal volume across all four monkeys and normal hippocampal volume is shown in Figure 2.

Assessment apparatus. Monkeys were tested using a touchscreen computer for display of stimuli and a linked pellet dispenser for delivery of rewards. At the completion of each correct trial, a $190 \mathrm{mg}$ flavored pellet was dispensed into a food cup located below the touchscreen within reach of the monkey. The apparatus also contained a sealed metal lunch box, which automatically opened upon completion of the final trial of the day. For further details, see Mitchell et al. (2007).

Behavioral task. Monkeys were tested in the object-in-place scenes task (Gaffan, 1994; Fig. 3). The scene was composed of a randomly colored background, a single large alphanumeric character, and a random number of differently colored and oriented ellipse segments. Two alphanu- meric characters (objects) of randomly determined color and font were shown in the foreground of each scene and randomly determined for each scene. The colors of the scene elements and objects were constrained to ensure visibility via a minimum color difference between each object and each other element of the scene. One of the two foreground objects was associated with reward (a single pellet). Because all elements were randomly determined for each scene that was composed, it was unlikely (although not impossible) that a specific element that appeared in one scene, for example the rewarded object, would also appear in another scene. Monkeys had to learn to respond by touching the character that was associated with reward for each scene. Thus, the task essentially involves learning a series of object discrimination problems, in which each pair of objects to be discriminated is associated with unique spatial locations in a unique visual scene. These object-in-place scene discrimination problems are learned much more rapidly than discriminations between similar objects presented against a neutral background or in randomly varying scenes (Gaffan, 1994). The rapid learning of object discriminations embedded within unique visual scenes captures a "snapshot" element of human episodic memory (Gaffan, 1994; Aggleton et al., 2000; Browning et al., 2005).

Training. Monkeys were initially trained to touch foreground objects and avoid touching background objects. Following pretraining, monkeys were trained on 25 sequentially presented scenes in a single testing session, with the same scenes presented in each test session across days. This continued for at least 10 sessions. Next the monkeys were given 50 sequentially presented scenes (the previous set of 25 plus 25 new ones) and tested for a minimum of 10 sessions, again with the same 50 scenes presented across days. Following this stage, monkeys were given 100 sequentially presented scenes (the previous 50 plus 50 new ones) in a single session. Training continued until monkeys reached a predefined criterion of $90 \%$ performance on 2 consecutive days of testing. In this way, monkeys were acclimated to responding to a large list of scene problems presented across days of testing. Following this stage, all testing sessions involved 100 scene discrimination problems. Monkeys were sequentially tested on three additional new sets of 100 scene discrimination problems (Sets 1,2, and 3), such that a minimum performance of $90 \%$ on 2 consecutive days of testing was required on a set before moving on to the next set of scenes. A touch to the correct object resulted the object flashing for $2 \mathrm{~s}$, and the delivery of a flavored pellet into the cup. A touch to the incorrect object led to the screen immediately turning black, and an increased intertrial interval of $10 \mathrm{~s}$. In this case a correction trial was 
Table 1. Hippocampal lesion extent

\begin{tabular}{|c|c|c|c|c|c|c|}
\hline $\begin{array}{l}\text { Hippocampal } \\
\text { subregion }\end{array}$ & $\begin{array}{l}\text { Left hemisphere } \\
\text { remaining volume }\end{array}$ & $\begin{array}{l}\text { Right hemisphere } \\
\text { remaining volume }\end{array}$ & $\begin{array}{l}\text { Bilateral } \\
\text { remaining volume }\end{array}$ & $\begin{array}{l}\text { Left hemisphere } \\
\text { lesion, \% }\end{array}$ & $\begin{array}{l}\text { Right hemisphere } \\
\text { lesion, } \%\end{array}$ & $\begin{array}{l}\text { Total } \\
\text { lesion, \% }\end{array}$ \\
\hline \multicolumn{7}{|c|}{ Whole hippocampal complex } \\
\hline Atlas & 268,144 & 268,665 & 536,809 & & & \\
\hline Mean & 140,600 & 115,858 & 256,457 & 47.57 & 56.88 & 52.23 \\
\hline $\mathrm{H} 1$ & 129,741 & 84,877 & 214,618 & 51.62 & 68.41 & 60.02 \\
\hline $\mathrm{H} 2$ & 159,535 & 158,787 & 318,322 & 40.50 & 40.90 & 40.70 \\
\hline H3 & 94,769 & 89,512 & 184,281 & 64.66 & 66.68 & 65.67 \\
\hline $\mathrm{H} 4$ & 178,354 & 130,254 & 308,608 & 33.49 & 51.52 & 42.51 \\
\hline \multicolumn{7}{|l|}{ CA1-3 } \\
\hline Atlas & 166,095 & 169,369 & 335,464 & & & \\
\hline Mean & 83,249 & 66,185 & 149,435 & 49.88 & 60.92 & 55.45 \\
\hline H1 & 90,287 & 43,135 & 133,422 & 45.64 & 74.53 & 60.23 \\
\hline $\mathrm{H} 2$ & 88,939 & 91,774 & 180,713 & 46.45 & 45.81 & 46.13 \\
\hline H3 & 45,960 & 44,926 & 90,886 & 72.33 & 73.47 & 72.91 \\
\hline $\mathrm{H} 4$ & 107,811 & 84,906 & 192,717 & 35.09 & 49.87 & 42.55 \\
\hline \multicolumn{7}{|l|}{ Dentate gyrus } \\
\hline Atlas & 67,812 & 62,992 & 130,804 & & & \\
\hline Mean & 49,247 & 38,987 & 88,234 & 27.38 & 38.11 & 32.55 \\
\hline $\mathrm{H} 1$ & 31,487 & 35,923 & 67,410 & 53.57 & 42.97 & 48.46 \\
\hline $\mathrm{H} 2$ & 58,038 & 51,448 & 109,486 & 14.41 & 18.33 & 16.30 \\
\hline H3 & 44,304 & 33,242 & 77,546 & 34.67 & 47.23 & 40.72 \\
\hline $\mathrm{H} 4$ & 63,157 & 35,335 & 98,492 & 6.86 & 43.91 & 24.70 \\
\hline \multicolumn{7}{|c|}{ Subicular complex } \\
\hline Atlas & 34,237 & 36,304 & 70,541 & & & \\
\hline Mean & 8,104 & 10,685 & 18,789 & 76.33 & 70.57 & 73.36 \\
\hline $\mathrm{H} 1$ & 7,967 & 5,819 & 13,786 & 76.73 & 83.97 & 80.46 \\
\hline $\mathrm{H} 2$ & 12,558 & 15,565 & 28,123 & 63.32 & 57.13 & 60.13 \\
\hline H3 & 4,505 & 11,344 & 15,849 & 86.84 & 68.75 & 77.53 \\
\hline $\mathrm{H} 4$ & 7,386 & 10,013 & 17,399 & 78.43 & 72.42 & 75.33 \\
\hline
\end{tabular}

The percentage of lesion coverage for each monkey $(\mathrm{H1}, \mathrm{H2}, \mathrm{H3}, \mathrm{H} 4)$ was estimated by registering Nissl-stained histological sections to atlas sections, and subtracting the remaining hippocampal volume from the atlas volume. This may be an underestimate of the true extent of the lesion as some damaged cells are likely included in the remaining hippocampal volume, rather than the lesion volume. Raw volume measurements are in arbitrary units (atlas dimensions).

administered, such that the monkey was represented with the scene, but with only the correct option present. Touches to the scene background resulted in the screen turning black, and the trial being restarted.

Monkeys were tested preoperatively on the three sets of 100 scene discrimination problems on 3 consecutive days, on average 82, 46, and $13 \mathrm{~d}$ following the last day of training on each set of scenes, respectively. In these tests, each scene was presented once per session, with Sets 1, 2, and 3 presented across consecutive days.

Following the final hippocampal surgery, monkeys were given $14 \mathrm{~d}$ recovery before testing resumed. On the first postoperative testing day, monkeys were shown single objects on the screen and rewarded for touching them, to become reacquainted with the testing apparatus. On each of the following 3 days (on average 113, 78, and $45 \mathrm{~d}$ following the last day of training on each set of scenes, respectively, and on average $31 \mathrm{~d}$ following the preoperative test), tests on one of the sets of 100 scene discrimination problems occurred, as in the preoperative testing phase. Following the retention test, monkeys learned a new fourth set of 100 scenes (Set 4) to the same criterion of $90 \%$ performance on 2 consecutive days, presented in the same way as preoperative learning.

Statistical analysis. The retrograde behavioral data were analyzed using repeated-measures ANOVA, with group, time, and set as fixed effects and individual monkeys treated as random effects. For the postoperative new scene learning, a $t$ test (not assuming equal variances) was used to assess the effect of lesion on the number of errors that occurred during learning until criterion was reached. To analyze rates of postoperative learning, errors per session across learning of the last preoperatively learned set of scenes (Set 3) and the postoperatively learned set of scenes (Set 4) were submitted to a linear mixed models analysis implemented in $\mathrm{R}$ version 3.5.0 using packages lme4 and lmerTest (Bates et al., 2015; Kuznetsova et al., 2017; R Core Team, 2018) with errors per session as the dependent variable and lesion group, preoperative versus postoperative training set, and session as fixed factors, and monkey as a random factor, with random slopes and intercepts for each monkey. This analysis accommo- dated the different number of sessions for each monkey during learning, as each set was trained to criterion.

\section{Results}

Neurotoxic hippocampal lesions impaired retention of preoperatively acquired memories, regardless of the time before surgery the memories were learned. Errors made in preoperative and postoperative single-trial retention tests, performed in identical fashion, showed a substantial impact of surgery in monkeys with hippocampal damage, whereas retention was similar in controls tested twice separated by a period of rest. Repeated-measures ANOVA on errors in retention test revealed significant main effects of group $\left(F_{(1,15)}=\right.$ 9.99, $p=0.006)$, pre/postop test $\left(F_{(1,15)}=28.14, p<0.0005\right)$, and, critically, their interaction $\left(F_{(1,15)}=8.894, p=0.009\right.$; Fig. $\left.4 A, B\right)$. There was a main effect of problem set, reflecting better retention of scenes learned closer to the time of surgery $\left(F_{(2,15)}=31.17, p<\right.$ $0.0005)$, but this effect did not interact with any others $\left(F_{(2,30)}\right.$ values $<1.67$, $p$ values $>0.21$ ).

Errors to criterion in new learning of a set of another 100 scene problems were not significantly different between control monkeys and monkeys with neurotoxic hippocampal lesions $\left(t_{(\sim 7.08)}=0.235\right.$, $p=0.821$; Fig. $4 C$ ). In terms of rate of acquisition, linear mixed models analysis of errors per session during learning of the last preoperative (Set 3) and postoperative (Set 4) sets of scenes revealed a main effect of session indicating learning across test sessions $\left(F_{(1, \sim 14.4)}=69.4, p<0.0005\right.$, but no main effects of lesion group, pre vs postoperative training set, interaction of these 2 factors, or interactions of these effects with session: $F_{(1, \sim 12.6-14.7)}$ values $<1.73$, $p$ values $>0.21$ ), indicating that monkeys with hippocampal lesions were not slower at learning of the postoperative set compared with 
their own performance on the preoperative set, which would be indicated by an interaction of lesion with preoperative versus postoperative training or of lesion, preoperative versus postoperative training, and session. Errors per sessions for the first eight sessions of training on both Sets 3 and 4 are shown in Figure $4 D$; data presentation is truncated at Session 8 because this is the first session in which any monkey reached criterion on any problem set.

The number of presentations of a particular stimulus per monkey was not explicitly controlled, as monkeys continued on a particular set of scenes until they reached criterion. However, the two groups did not significantly differ in the number of times they viewed each scene based on Wilcoxon rank sum tests (Table 2).

\section{Discussion}

Rhesus monkeys with bilateral neurotoxic lesions limited to the hippocampus were impaired in retrieval of object-in-place scene problems learned before the lesion, but could learn a new set of scene problems at the same rate as controls. Thus, for complex visual scenes, the primate hippocampus is necessary for retrieval, but not new learning. This is congruent with a role for the hippocampus in consolidation of visual memories, to the extent that retrieval of scene problems learned months before the hippocampal lesion was impaired. Perhaps surprisingly, there was no indication of any gradient of retrograde amnesia, with equivalent impairment of scenes learned at each time point trained before surgery. This pattern of results is consistent with the multiple trace theory of hippocampal involvement in episodic memory (Moscovitch et al., 2005), which predicts dependence of detailed episodic memory on the hippocampus regardless of the age of the memory. It has been suggested, that, where possible, memories are incorporated into preexisting networks of knowledge, called "schemas" (Piaget, 1929), and that in contrast to multiple trace theory, the incorporation of new memories into preexisting schemas may allow memories to quickly become independent from the hippocampus (Tse et al., 2011). The experience of the monkeys with the scenes task and stimuli did not appear to confer any "schematization" on their memories that rendered them hippocampalindependent.

With regard to the absence of a temporal gradient, it is important to note that we did not explicitly control time before surgery as an experimental variable, with each monkey moving on to the next set of scene problems once the current set was learned to criterion. Acquisition of the most remote set began $\sim 4$ months before surgery and the most recent set 1 month before surgery. This spans a time interval over which object discrimination problems have been reported to become hippocampal-independent in macaque monkeys (Zola-Morgan and Squire, 1990).

Considerable work has been directed at the question of whether the hippocampus plays a time-limited role in memory storage. In general following hippocampal damage or inactiva-
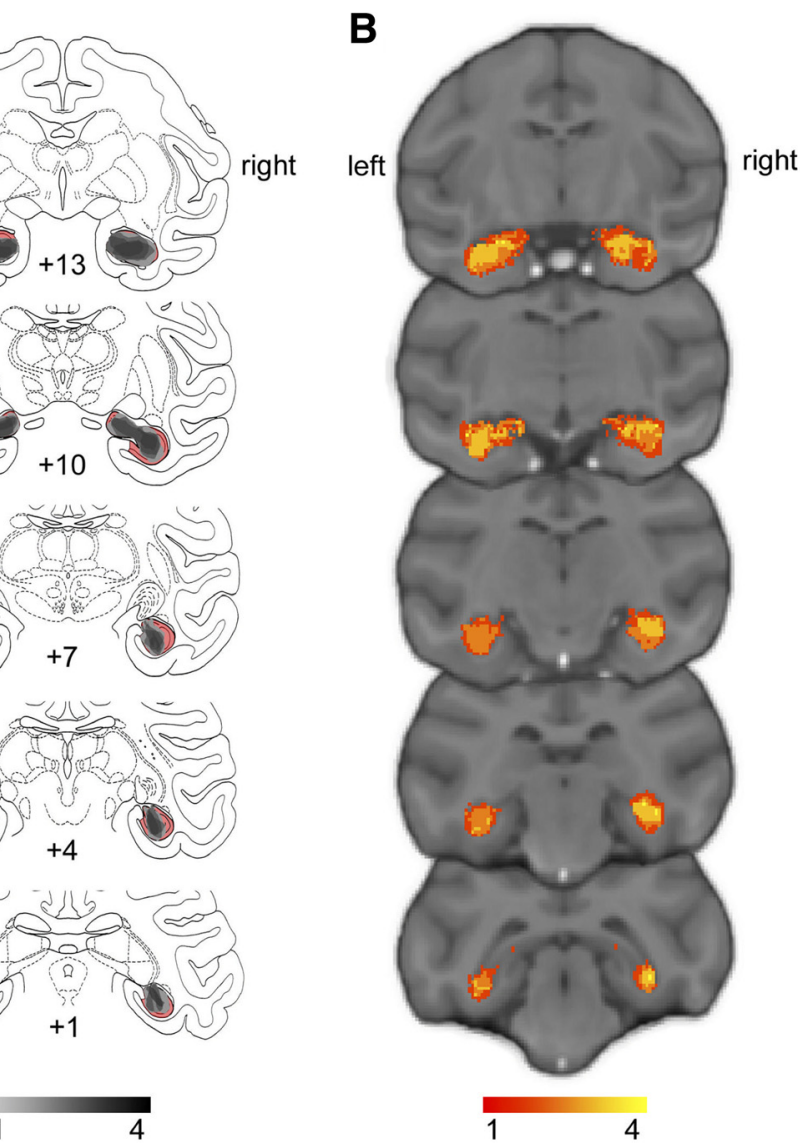

1

4

Figure 2. Extent and variability of hippocampal lesions. A, Sketch of hippocampal size based on histology (Nissl-stained volume is shown for the four monkeys indicating shrinkage of the hippocampus bilaterally in all monkeys. $\boldsymbol{B}$, T2-weighted hypersignal $6 \mathrm{~d}$ after surgery indicating local inflammation in the hippocampus. Overlap is shown for the four monkeys.

tion, studies in rodents have found temporally graded retrograde amnesia of socially transmitted food preferences and temporally extensive retrograde amnesia in spatial learning, both accompanied by anterograde impairments, but mixed results in contextual fear conditioning (Maren et al., 1997; Anagnostaras et al., 1999; Winocur et al., 2013b; for review, see Winocur et al., 2013a). In this context, a temporally extensive retrograde amnesia for scene problems accompanied by normal anterograde new learning is unusual. An important limitation to any conclusions about a retrograde gradient or lack thereof is that we performed single-trial retention tests for all scenes before surgery. This allowed for a direct comparison of preoperative and postoperative retention, but also may have rendered all of the scene problems "recent" and subject to reconsolidation/re-encoding processes that would have re-engaged the hippocampus. As a consequence, the critical variable for the presence of retrograde amnesia may not be the time since a memory was learned, but the time since it was retrieved. This issue bears direct investigation in future studies, perhaps by excluding some scene problems from preoperative retention tests to compare effects of lesions or temporary inactivations on "reactivated" scenes versus scenes that had not been tested since learning was complete. Because postoperative retention tests showed time-dependent forgetting in control monkeys and performance was comparable between preoperative and postoperative retention, any new learning induced by the preoperative retention test would seem to be small. 

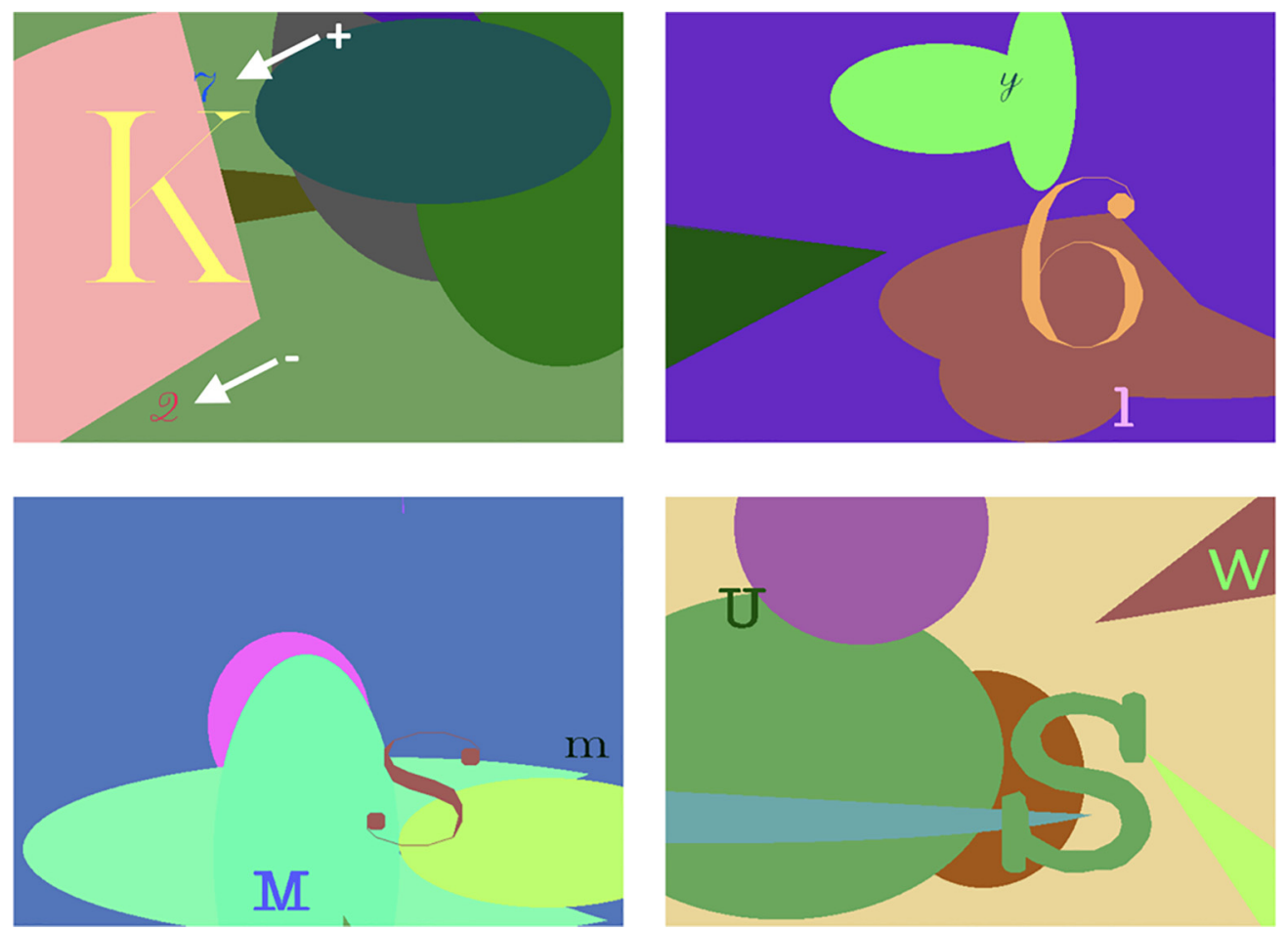

Figure 3. Object-in-place scenes task. Four example scenes from the object-in-place scenes task. Monkeys learned to discriminate two small foreground objects (alphanumeric characters of a random font and color, pointed to by white arrows in the top left scene), so as to select the object associated with a reward (signaled by here by the + arrow) and avoid touching the unrewarded object (signaled by here by the - arrow). Within a particular scene locations of objects and their reward assignments were always stable, but rewarded versus non-rewarded objects were randomly assigned across scenes. See text for details on training procedure.
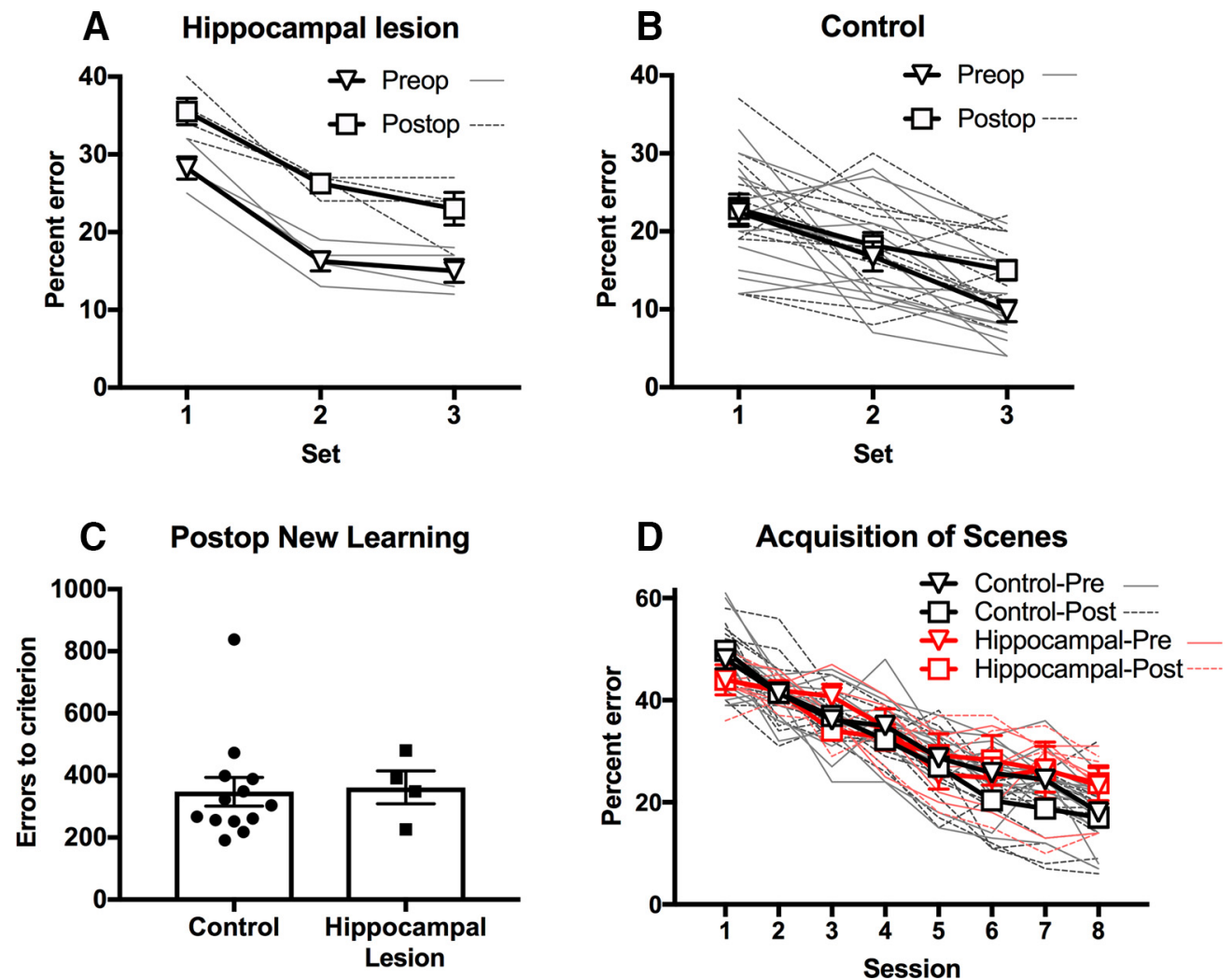

Figure 4. Effects of hippocampal lesions on object-in-place scene memory. $A$, Retrograde memory impairment in monkeys with hippocampal lesions. Monkeys made a higher proportion of errors on recognition of previously learned object-in-place scenes following hippocampal lesions. $\boldsymbol{B}$, This effect significantly differed from unoperated control monkeys, tested at equivalent time points, in whom no effect of (preoperative vs postoperative equivalent) time was found. $C, \boldsymbol{D}$, No anterograde memory impairment in monkeys with hippocampal lesions. Hippocampal lesions caused no discernable impairment in learning of new scenes, as seen through the number of errors committed en route to reaching the preset criterion $(\boldsymbol{C})$, and the rate of learning across sessions ( $\boldsymbol{D})$. Error bars represent standard errors of the mean. Overlaid lines (panels $\boldsymbol{A}, \boldsymbol{B}, \boldsymbol{D}$ ) and points (panel $\boldsymbol{C}$ ) represent data from individual monkeys. 


\begin{tabular}{|c|c|c|c|c|}
\hline $\begin{array}{l}\text { No. of } \\
\text { presentations } \\
\text { of individual scenes, } \\
\text { median (range) }\end{array}$ & $\begin{array}{l}\text { Hippocampal } \\
\text { lesion group }\end{array}$ & Controls & $\begin{array}{l}\text { Test statistic, } \\
\text { rank sum }\end{array}$ & $p$ \\
\hline Set 1 (prelesion) & $18(15-31)$ & $23(11-45)$ & 30.5 & 0.559 \\
\hline Set 2 (prelesion) & $20.5(17-26)$ & $17(11-26)$ & 49.5 & 0.131 \\
\hline Set 3 (prelesion) & $16(10-23)$ & $13(9-29)$ & 40.5 & 0.643 \\
\hline Set 4 (postlesion) & $15(10-21)$ & $12(8-37)$ & 41 & 0.601 \\
\hline
\end{tabular}

The effect of hippocampal lesions on retention and new learning of object-in-place scene problems in this study was qualitatively and quantitatively almost identical to that of ablations of the anterior entorhinal cortex in an earlier study (Mitchell et al., 2008). This suggests that retrieval of visual scene memories occurs via corticocortical interactions between the hippocampus and entorhinal cortex. Supporting this conclusion is the observation that transection of the fornix is without effect on retrieval of preoperatively learned scenes in our paradigm (unpublished data). It also supports the view that cortical and subcortical structures, broadly speaking, have distinct roles in memory acquisition and retrieval (Mitchell et al., 2008; Baxter, 2013). That the surgical procedure itself had no effect on its own, independently of hippocampal damage, on memory retrieval is supported by the absence of effects of neurotoxic mediodorsal thalamic lesions (Mitchell and Gaffan, 2008) or fornix lesions (unpublished data) on postoperative retention of preoperatively learned object-inplace scenes.

New learning of scene problems was unimpaired in the monkeys with neurotoxic hippocampal lesions. As with other cortical structures in the primate brain (Thornton et al., 1997; Mitchell et al., 2008), there appears to be a substantial capacity for intact, remaining cortical regions to acquire new memories after hippocampal damage (Nosarti and Froudist-Walsh, 2016). This may relate to the development of alternative behavioral strategies for new learning after focal brain damage (Manns and Squire, 1999; Squire, 2004), the plastic reorganization of brain networks for memory acquisition (Croxson et al., 2012), or both. We did not ascertain whether newly acquired scene memories after hippocampal damage were as enduring as those in monkeys with an intact hippocampus (Zelikowsky et al., 2012), or whether they were represented differently, perhaps more inflexibly (cf. Bayley and Squire, 2002; Bayley et al., 2005a). This also is germane to the question of whether object-in-place scene memories might have varied in detail before or after the lesion, which could have affected hippocampal involvement (Moscovitch et al., 2005; Winocur et al., 2010; Sekeres et al., 2018).

Studies in humans with amnesia (Ryan et al., 2000; Hannula et al., 2007; Bird and Burgess, 2008) and animals with hippocampal manipulations (Howard and Eichenbaum, 2013) suggest that there are certain kinds of representations that require the hippocampus, including but not limited to conjunctions of spatial and temporal information. The lack of impairment in new learning of object-in-scene problems across days in the present study is perhaps surprising in light of impaired learning of relations among elements in a scene in patients with amnesia (Ryan et al., 2000; Chau et al., 2011), although this may reflect differences in task design as well as lesion specificity to the hippocampus. Intact learning of object-in-place scene problems in monkeys with hippocampal lesions also contrasts with impairments following se- lective hippocampal damage in monkeys in more purely spatial tasks (Murray and Mishkin, 1998; Murray et al., 1998; Hampton et al., 2004; Lavenex et al., 2006). It is also possible that under normal conditions encoding of memories is distributed throughout the hippocampus, but in the lesioned hippocampus memories are encoded using the surviving hippocampal tissue (Moser and Moser, 1998). In those circumstances, hippocampal lesions would prevent animals from accessing the full hippocampal representation of memories encoded prelesion, but not of those encoded postlesion (Moser and Moser, 1998).

An additional possibility is that memory encoding and retrieval differentially engage distinct hippocampal subfields. We attempted to estimate the damage to the dentate gyrus, CA1-3 and subicular complex, and noted that the subicular complex appeared most affected by the lesions. Maren (1999) found that rats with lesions focused on the subiculum, with some additional damage to hippocampal and entorhinal subregions, were severely impaired at recalling contextual fear memories that were learned before the lesion, but only exhibited a minor deficit in learning new contextual fear memories. Nonetheless, the rats were severely impaired at learning and remembering a tone-shock association (Maren, 1999). This pattern of contextual fear memory deficits in rats with lesions focused on the subiculum resembles the retrograde scene memory deficits observed here. As such, the suggestion from that paper that certain types of memories may be encoded postlesion without requiring the hippocampus is a possibility.

These accounts of differential effects of hippocampal lesions on retrograde and anterograde memory, however, does not explain double dissociations between cortical lesions that impair retrieval but not new learning, and lesions of subcortical structures that impair new learning but not retrieval (Mitchell et al., 2008). Within-session scene learning, as opposed to learning of problems across days, might also be more sensitive to effects of hippocampal damage, as within-session scene learning is impaired by fornix lesions (Gaffan, 1994). Learning scene problems across days is not generally insensitive to lesion effects, as shown by effects of damage to mediodorsal thalamus on scene problems given in this manner (Mitchell and Gaffan, 2008).

On a broader level, our findings suggest that paradigms for studying memory consolidation and the neural mechanisms of systems consolidation would benefit from extending beyond the investigation of single (or very few) memories that are acquired in a small number of trials. This is obviously useful for mechanistic studies in which the time of memory acquisition needs to be precisely known, as for tracking time-dependent biochemical cascades. However, the dynamics of large numbers of unique visual memories, acquired concurrently over a period of time, may engage different mechanisms and may place different demands on different brain structures, or networks of brain structures, as a function of the age of the memory.

\section{References}

Aggleton JP, McMackin D, Carpenter K, Hornak J, Kapur N, Halpin S, Wiles CM, Kamel H, Brennan P, Carton S, Gaffan D (2000) Differential cognitive effects of colloid cysts in the third ventricle that spare or compromise the fornix. Brain 123:800-815. CrossRef Medline

Anagnostaras SG, Maren S, Fanselow MS (1999) Temporally graded retrograde amnesia of contextual fear after hippocampal damage in rats: withinsubjects examination. J Neurosci 19:1106-1114. CrossRef Medline

Augustinack JC, van der Kouwe AJ, Salat DH, Benner T, Stevens AA, Annese J, Fischl B, Frosch MP, Corkin S (2014) HM's contributions to neuroscience: a review and autopsy studies. Hippocampus 24:1267-1286. CrossRef Medline 
Bartsch T, Deuschl G (2010) Transient global amnesia: functional anatomy and clinical implications. Lancet Neurol 9:205-214. CrossRef Medline

Bartsch T, Döhring J, Rohr A, Jansen O, Deuschl G (2011) CA1 neurons in the human hippocampus are critical for autobiographical memory, mental time travel, and autonoetic consciousness. Proc Natl Acad Sci U S A 108:17562-17567. CrossRef Medline

Bates D, Machler M, Bolker B, Walker S (2015) Fitting linear mixed-effects models using lme4. J Stat Softw 67:1-48. CrossRef

Baxter MG (2013) Mediodorsal thalamus and cognition in non-human primates. Front Syst Neurosci 7:38. CrossRef Medline

Baxter MG, Murray EA (2001) Opposite relationship of hippocampal and rhinal cortex damage to delayed nonmatching-to-sample deficits in monkeys. Hippocampus 11:61-71. CrossRef Medline

Bayley PJ, Squire LR (2002) Medial temporal lobe amnesia: gradual acquisition of factual information by nondeclarative memory. J Neurosci 22: 5741-5748. CrossRef Medline

Bayley PJ, Frascino JC, Squire LR (2005a) Robust habit learning in the absence of awareness and independent of the medial temporal lobe. Nature 436:550-553. CrossRef Medline

Bayley PJ, Gold JJ, Hopkins RO, Squire LR (2005b) The neuroanatomy of remote memory. Neuron 46:799-810. CrossRef Medline

Bird CM, Burgess N (2008) The hippocampus and memory: insights from spatial processing. Nat Rev Neurosci 9:182-194. CrossRef Medline

Broadbent NJ, Gaskin S, Squire LR, Clark RE (2010) Object recognition memory and the rodent hippocampus. Learn Mem 17:5-11. CrossRef Medline

Browning PG, Easton A, Buckley MJ, Gaffan D (2005) The role of prefrontal cortex in object-in-place learning in monkeys. Eur J Neurosci 22:32813291. CrossRef Medline

Chau VL, Murphy EF, Rosenbaum RS, Ryan JD, Hoffman KL (2011) A flicker change detection task reveals object-in-scene memory across species. Front Behav Neurosci 5:58. CrossRef Medline

Cowansage KK, Shuman T, Dillingham BC, Chang A, Golshani P, Mayford M (2014) Direct reactivation of a coherent neocortical memory of context. Neuron 84:432-441. CrossRef Medline

Croxson PL, Browning PG, Gaffan D, Baxter MG (2012) Acetylcholine facilitates recovery of episodic memory after brain damage. J Neurosci 32: 13787-13795. CrossRef Medline

Ding HK, Teixeira CM, Frankland PW (2008) Inactivation of the anterior cingulate cortex blocks expression of remote, but not recent, conditioned taste aversion memory. Learn Mem 15:290-293. CrossRef Medline

Doré FY, Thornton JA, White NM, Murray EA (1998) Selective hippocampal lesions yield nonspatial memory impairments in rhesus monkeys. Hippocampus 8:323-329. CrossRef Medline

Forwood SE, Winters BD, Bussey TJ (2005) Hippocampal lesions that abolish spatial maze performance spare object recognition memory at delays of up to 48 hours. Hippocampus 15:347-355. CrossRef Medline

Frankland PW, Bontempi B, Talton LE, Kaczmarek L, Silva AJ (2004) The involvement of the anterior cingulate cortex in remote contextual fear memory. Science 304:881-883. CrossRef Medline

Frankland PW, Ding HK, Takahashi E, Suzuki A, Kida S, Silva AJ (2006) Stability of recent and remote contextual fear memory. Learn Mem 13: 451-457. CrossRef Medline

Gaffan D (1994) Scene-specific memory for objects: a model of episodic memory impairment in monkeys with fornix transection. J Cogn Neurosci 6:305-320. CrossRef Medline

Goshen I, Brodsky M, Prakash R, Wallace J, Gradinaru V, Ramakrishnan C, Deisseroth K (2011) Dynamics of retrieval strategies for remote memories. Cell 147:678-689. CrossRef Medline

Hampton RR, Hampstead BM, Murray EA (2004) Selective hippocampal damage in rhesus monkeys impairs spatial memory in an open-field test. Hippocampus 14:808-818. CrossRef Medline

Hannula DE, Ryan JD, Tranel D, Cohen NJ (2007) Rapid onset relational memory effects are evident in eye movement behavior, but not in hippocampal amnesia. J Cogn Neurosci 19:1690-1705. CrossRef Medline

Howard MW, Eichenbaum H (2013) The hippocampus, time, and memory across scales. J Exp Psychol Gen 142:1211-1230. CrossRef Medline

Kapur N, Brooks DJ (1999) Temporally-specific retrograde amnesia in two cases of discrete bilateral hippocampal pathology. Hippocampus 9:247254. CrossRef Medline

Kuznetsova A, Brokhoff PB, Christensen RHB (2017) lmer Test package: tests in linear mixed effects models. J Stat Softw 82:1-26. CrossRef
Lavenex PB, Amaral DG, Lavenex P (2006) Hippocampal lesion prevents spatial relational learning in adult macaque monkeys. J Neurosci 26: 4546-4558. CrossRef Medline

Málková L, Lex CK, Mishkin M, Saunders RC (2001) MRI-based evaluation of locus and extent of neurotoxic lesions in monkeys. Hippocampus 11: 361-370. CrossRef Medline

Manns JR, Squire LR (1999) Impaired recognition memory on the doors and people test after damage limited to the hippocampal region. Hippocampus 9:495-499. CrossRef Medline

Maren S (1999) Neurotoxic or electrolytic lesions of the ventral subiculum produce deficits in the acquisition and expression of Pavlovian fear conditioning in rats. Behav Neurosci 113:283-290. CrossRef Medline

Maren S, Aharonov G, Fanselow MS (1997) Neurotoxic lesions of the dorsal hippocampus and Pavlovian fear conditioning in rats. Behav Brain Res 88:261-274. CrossRef Medline

Mitchell AS, Gaffan D (2008) The magnocellular mediodorsal thalamus is necessary for memory acquisition, but not retrieval. J Neurosci 28:258 263. CrossRef Medline

Mitchell AS, Baxter MG, Gaffan D (2007) Dissociable performance on scene learning and strategy implementation after lesions to magnocellular mediodorsal thalamic nucleus. J Neurosci 27:11888-11895. CrossRef Medline

Mitchell AS, Browning PG, Wilson CR, Baxter MG, Gaffan D (2008) Dissociable roles for cortical and subcortical structures in memory retrieval and acquisition. J Neurosci 28:8387-8396. CrossRef Medline

Moscovitch M, Rosenbaum RS, Gilboa A, Addis DR, Westmacott R, Grady C, McAndrews MP, Levine B, Black S, Winocur G, Nadel L (2005) Functional neuroanatomy of remote episodic, semantic and spatial memory: a unified account based on multiple trace theory. J Anat 207:35-66. CrossRef Medline

Moser MB, Moser EI (1998) Distributed encoding and retrieval of spatial memory in the hippocampus. J Neurosci 18:7535-7542. CrossRef Medline

Murray EA, Mishkin M (1998) Object recognition and location memory in monkeys with excitotoxic lesions of the amygdala and hippocampus. J Neurosci 18:6568-6582. CrossRef Medline

Murray EA, Baxter MG, Gaffan D (1998) Monkeys with rhinal cortex damage or neurotoxic hippocampal lesions are impaired on spatial scene learning and object reversals. Behav Neurosci 112:1291-1303. CrossRef Medline

Nosarti C, Froudist-Walsh S (2016) Alterations in development of hippocampal and cortical memory mechanisms following very preterm birth. Dev Med Child Neurol 58:35-45. CrossRef Medline

Piaget J (1929) The child's conception of the world. Oxford: Harcourt, Brace.

R Core Team (2018) R: a language and environment for statistical computing. R Foundation for Statistical Computing, Vienna, Austria.

Reed JM, Squire LR (1998) Retrograde amnesia for facts and events: findings from four new cases. J Neurosci 18:3943-3954. CrossRef Medline

Ryan JD, Althoff RR, Whitlow S, Cohen NJ (2000) Amnesia is a deficit in relational memory. Psychol Sci 11:454-461. CrossRef Medline

Saunders RC, Aigner TG, Frank JA (1990) Magnetic resonance imaging of the rhesus monkey brain: use for stereotactic neurosurgery. Exp Brain Res 81:443-446. Medline

Scoville WB, Milner B (1957) Loss of recent memory after bilateral hippocampal lesions. J Neurol Neurosurg Psychiatry 20:11-21. CrossRef Medline

Sekeres MJ, Winocur G, Moscovitch M (2018) The hippocampus and related neocortical structures in memory transformation. Neurosci Lett. Advance online publication. doi: 10.1016/j.neulet.2018.05.006. Medline

Squire LR (2004) Memory systems of the brain: a brief history and current perspective. Neurobiol Learn Mem 82:171-177. CrossRef Medline

Tanaka KZ, Pevzner A, Hamidi AB, Nakazawa Y, Graham J, Wiltgen BJ (2014) Cortical representations are reinstated by the hippocampus during memory retrieval. Neuron 84:347-354. CrossRef Medline

Tayler KK, Tanaka KZ, Reijmers LG, Wiltgen BJ (2013) Reactivation of neural ensembles during the retrieval of recent and remote memory. Curr Biol 23:99-106. CrossRef Medline

Teixeira CM, Pomedli SR, Maei HR, Kee N, Frankland PW (2006) Involvement of the anterior cingulate cortex in the expression of remote spatial memory. J Neurosci 26:7555-7564. CrossRef Medline

Thornton JA, Rothblat LA, Murray EA (1997) Rhinal cortex removal produces amnesia for preoperatively learned discrimination problems but fails to disrupt postoperative acquisition and retention in rhesus monkeys. J Neurosci 17:8536-8549. CrossRef Medline

Tse D, Takeuchi T, Kakeyama M, Kajii Y, Okuno H, Tohyama C, Bito H, 
Morris RG (2011) Schema-dependent gene activation and memory encoding in neocortex. Science 333:891-895. CrossRef Medline

Winocur G, Moscovitch M, Bontempi B (2010) Memory formation and long-term retention in humans and animals: convergence towards a transformation account of hippocampal-neocortical interactions. Neuropsychologia 48:2339-2356. CrossRef Medline

Winocur G, Moscovitch M, Sekeres MJ (2013a) Factors affecting graded and ungraded memory loss following hippocampal lesions. Neurobiol Learn Mem 106:351-364. CrossRef Medline

Winocur G, Sekeres MJ, Binns MA, Moscovitch M (2013b) Hippocampal lesions produce both nongraded and temporally graded retrograde amnesia in the same rat. Hippocampus 23:330-341. CrossRef Medline

Winters BD, Forwood SE, Cowell RA, Saksida LM, Bussey TJ (2004) Double dissociation between the effects of peri-postrhinal cortex and hippocampal lesions on tests of object recognition and spatial memory: heterogeneity of function within the temporal lobe. J Neurosci 24:5901-5908. CrossRef Medline

Zelikowsky M, Bissiere S, Fanselow MS (2012) Contextual fear memories formed in the absence of the dorsal hippocampus decay across time. J Neurosci 32:3393-3397. CrossRef Medline

Zola SM, Squire LR, Teng E, Stefanacci L, Buffalo EA, Clark RE (2000) Impaired recognition memory in monkeys after damage limited to the hippocampal region. J Neurosci 20:451-463. CrossRef Medline

Zola-Morgan SM, Squire LR (1990) The primate hippocampal formation: evidence for a time-limited role in memory storage. Science 250:288 -290. CrossRef Medline 